\title{
The public health and safety benefits of the Northern Territory's Living with Alcohol programme
}

\section{TIM STOCKWELL ${ }^{1}$, TANYA CHIKRITZHS ${ }^{1}$, DELIA HENDRIE ${ }^{2}$, RICHARD FORDHAM ${ }^{2}$, FAITH YING ${ }^{2}$, MIKE PHILLIPS ${ }^{1}$, JOANNE CRONIN ${ }^{3} \&$ BRIDIE O'REILLY ${ }^{4}$}

\author{
${ }^{1}$ National Drug Research Institute (Preventing Harmful Drug Use in Australia), \\ Curtin University, Western Australia, ${ }^{2}$ The Lewin-Fordham Group, Perth, Western \\ Australia, ${ }^{3}$ The WA Health Promotion Foundation and ${ }^{4} N T$ Government Living \\ With Alcohol programme, Perth, Western Australia
}

Abstract

An evaluation is presented of the impact of a comprehensive population-based alcohol harmreduction programme in the Northern Territory funded by a levy of 5 cents per standard drink which took effect from April 1992. The proceeds of the levy supported increased treatment, public education and other prevention activities. Towards the end of the study period (the first 4 years) other positive initiatives were introduced: the lowering of the legal limit for drivers to $0.05 \mathrm{mg} / \mathrm{ml}$ and a special levy on cask wine. Indicators of alcohol-related harm were tracked from 1980 to June 301996 and developed from hospital, mortality and road crash data. In each case appropriate control data from the same source was employed to control for other possible confounding effects. Alcohol aetiological fractions for major alcohol-related causes of death were estimated taking account of the level of high-risk alcohol use in the Northern Territory. Multiple linear regression and time-series analyses were employed to test for any effect coinciding with the introduction of LWA. There were reductions in estimated alcohol-caused deaths from acute conditions (road deaths

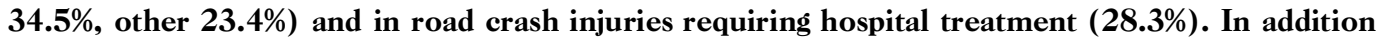
there were substantial reductions in per capita alcohol consumption and self-reported hazardous and harmful consumption via surveys. These reductions were evident immediately from the outset of the introduction of LWA and were largely sustained throughout the 4 years studied. The data reported here suggest that significant health and safety benefits accrued to the people of the

\footnotetext{
Tim Stockwell, Professor, National Drug Research Institute, (Preventing Harmful Drug Use in Australia), Curtin University of Technology, GPO Box U1987, Perth, 6845, Western Australia; Tanya Chikritzhs National Drug Research Institute, (Preventing Harmful Drug Use in Australia), Curtin University of Technology, GPO Box U1987, Perth, 6845, Western Australia; Delia Hendrie, The Lewin-Fordham Group, Perth, Western Australia; Richard Fordham MD, University of East Anglia, Norwich, UK; Faith Ying, Research Assistant, The LewinFordham Group, Perth, Western Australia; Mike Phillips, Honorary Senior Research Fellow, National Drug Research Institute (Preventing Harmful Drug Use in Australia), Curtin University of Technology, GPO Box U1987, Perth, 6845, Western Australia; Joanne Cronin, The WA Health Promotion Founation, Perth, Western Australia; Bridie O'Reilly MD, NT Government Living With Alcohol Programme, Perth, Western Australia. Correspondence to Tim Stockwell.
}

Received 21 September 2000; accepted for publication 27 February 2001. 
Northern Territory during the first 4 years of the Living With Alcohol programme. This benefit is likely to be due to several factors: the effect of the levy on alcohol consumption, other factors depressing alcohol consumption and the effect of the LWA programme itself. [Stockwell T, Chikritzhs T, Hendrie D, Fordham F, Ying F, Phillips M, Cronin J, O'Reilly B. The public health and safety benefits of the Northern Territory's Living With Alcohol programme. Drug Alcohol Rev 2001;20:167-180]

Key words: alcohol, prevention, taxation, treatment, road crashes, hospital episodes, mortality.

\section{Introduction}

This paper presents an evaluation of the impact of an alcohol harm reduction programme initiated in the Northern Territory (NT), a thinly populated although geographically substantial part of central and northern Australia. The total resident population of the NT during the study was approximately 180000 people. There were several unique features of both the programme and the manner of its evaluation which may make it of special interest for policy makers and researchers concerned to develop more effective strategies for reducing alcohol-related harm. The NT has for many years had the highest levels of hazardous alcohol consumption and of related problems such as violence and road trauma in Australia [1,2] and also among the highest by world standards [3]. The Living With Alcohol programme (LWA) was established with the aim of being a comprehensive public health strategy to address alcohol-related harm in the NT. It was originally funded by an additional levy on alcohol products containing more than $3 \%$ alcohol by volume. Other funding mechanisms were developed following a High Court ruling in 1997 which disallowed States and Territories from using licensing fees to raise tax revenue. The period of this evaluation covers 4 financial years prior to that High Court ruling when the LWA levy of 5 cents per standard drink was in effect [the precise rates for different beverages were: beer and pre-mixed spirits $\$ 0.20$ per litre; wine and cider $\$ 0.48$ per litre; spirits and fortified wines $\$ 1.60$ per litre].

There is growing interest in international alcohol epidemiology in the development of national systems for monitoring alcohol-related harm as a tool for guiding the development of effective public policy $[3,4]$. In Australia, national indicators of a range of key alcohol-caused harms are being developed with funding from the National Drug Strategic Framework. Early outcomes of this project include the publication of annual state-by-state estimates of alco- hol-caused deaths and serious alcohol-related road injuries $[1,2,5,6]$. The present evaluation represents an early opportunity to refine and apply indicators of serious alcohol-related harms to the evaluation of a major prevention initiative.

The LWA programme followed a general increase in community concern about alcohol in the late $1980 \mathrm{~s}$ which led to an influential report of a Select Committee being presented in 1991 to the Legislative Assembly. In this report it was estimated that the financial cost to the NT Government and the community from problems associated with the use of alcohol in 1988 was A $\$ 150$ million, or approximately $\$ 1000$ per adult resident [7]. Other evidence presented to the Select Committee emphasized the high levels of alcohol-related harm in the Territory, as indicated by per capita alcohol consumption being approximately $70 \%$ higher than elsewhere in Australia, one in two road deaths being alcohol-related (50\% higher than the national average); in 1989/1990 there were over 30000 incidents of people being taken into protective custody by police for public drunkenness, in 1991/1992 three-quarters of sentenced prisoners reported that alcohol was a factor in their offending and it was estimated that rates of alcohol-related deaths were three times the national average [8].

The present study employed a range of official data sources to create alcohol harm indicators as well as control indicators of cases unlikely to be alcoholrelated. Morbidity, mortality, road crash and alcohol consumption data were used. Data on hospital admissions were incomplete for the 4 years prior to this study and so are not reported here (see [5] for analyses of these data). The available harm indicators were then applied to address the question as to whether the 4 financial years following the introduction of the LWA levy were associated with a significant reduction in alcohol-related harm. It was also necessary to control for other significant initiatives during that time, 
including the introduction of a lower permitted BAC for drivers and a special levy on cask wine both introduced towards the end of the study period. A wide range of alcohol initiatives were introduced during the before and after LWA periods, as summarized below.

\section{The range of interventions associated with LWA}

The LWA programme was introduced during a remarkable period for alcohol prevention in the NT. While the 1980s were characterized by a loosening of restrictions on sales (e.g. increase in number of licences granted and a decrease in state liquor taxes from $16 \%$ to $11 \%$ ) the 1990 s saw a range of new controls being introduced, only some of which were directly the result of LWA. Many of the interventions made possible by the programme can claim to be evidence-based, as outlined below.

\section{Price increases}

The 5 cents per standard drink LWA levy increased the price of alcoholic drinks with more than $3 \%$ alcohol content by volume, as was confirmed by price surveys commissioned by the programme. Literature reviews have repeatedly identified raising the price of alcohol as one of the most consistently effective policy interventions available to government $[9,10]$. A further increase in the price of cask wine was introduced in July 1995 as a consequence of concern about excessive drinking associated with this cheapest of alcoholic beverages [11].

\section{More treatment in programmes}

The LWA levy was used for a variety of treatment, education and prevention activities, most of which could be expected to have had an effect on community levels of alcohol-related harm over and above the increase they caused in the price of alcohol. Once the programme was in full swing approximately $\$ 2$ million per annum extra was expended on treatment services for people with alcohol dependence and related problems. Holder \& Blose [12] found evidence that the amount of treatment activity for such people in a community is directly related to reductions in overall levels of problems at the population level. Even if these programmes only succeed temporarily in helping such people stop or substantially reduce their drinking, this is likely to have a beneficial effect on levels of serious social, health and economic costs given the high rate of such problems among candidates for alcohol treatment.

\section{More high profile prevention programmes}

The proceeds from the levy were also used to fund mass media education programmes both on drink driving and responsible service of alcohol on licensed premises. Reviews of mass media campaigns suggest that they can change behaviour and reduce harm when they complement significant amounts of on the ground community activity (e.g. [13]). It is noteworthy that during the LWA period there was increased enforcement both of drink driving and liquor licensing laws as well as supporting media for both activities. There is substantial support for the harm reducing effects of both the enforcement activities per se and also suggestive evidence that the media campaigns will further increase their efficacy $[14,15]$.

\section{Lowered legal blood alcohol content (BAC) for drivers}

Another important intervention unrelated to LWA was the introduction of the 0.05 legal limit for drivers in December 1994. This was mainly the result of a Commonwealth initiative that tied funding for road maintenance to the introduction of a range of measures to reduce road crashes, including the introduction of 0.05 . However, the ability of the NT government to use LWA funds for mass media campaigns supporting drink driving law enforcement is likely to have increased the effectiveness of this intervention for the reasons noted above.

\section{Restrictions on hours of trading for licensed premises}

Special mention should also be made of the various local licensing restrictions that were introduced during the LWA period of operation. These were in operation in particular areas during the study period, notably Tenant Creek and Alice Springs. While these were instigated mainly by the actions of local residents, the amendments to the Liquor Act and provision of funding from LWA to community groups may have increased the ability of local communities to petition for licensing changes. There is strong support for the effectiveness of local restrictions on alcohol's availability (e.g. $[9,16-18]$ ). These studies also show that 
problems are not significantly exported to other areas and that an overall reduction in problems can be expected to result.

In conclusion, the LWA programme provides a unique example of a community with exceptionally high levels of alcohol problems which then introduced a comprehensive range of prevention and harm reduction measures, many of which should have had a measurable impact on levels of harm. For the purposes of this evaluation it is important to note that while there was a clear start time of the introduction of the LWA levy, there were various other interventions independent of LWA which occurred prior and also during the 4-year-after period. There was also an increase in liquor licences granted in the preceding years. In the year prior to LWA, there was evidence of increased enforcement of liquor laws immediately prior to the introduction of LWA. The major interventions introduced subsequent to LWA, the cask wine levy and the new reduced permitted BAC level for drivers of $0.05 \mathrm{mg} / \mathrm{ml}$ occurred towards the end of the study period. LWA funded interventions, notably hardhitting commercials and increased treatment facilities, began mid-way through the intervention period. In some of the analyses reported below it was possible to control for the impact of these latter interventions that were unrelated to the LWA programme itself.

\section{Methods}

\section{Alcohol harm indicators}

The selection of harm indicators was facilitated by draft international guidelines established by the World Health Organization [4] and national guidelines as outlined by the National Expert Advisory Committee on Alcohol [19]. Australian studies employing and testing local level indicators of alcohol consumption and harm have been influential in the development of the national and international guidelines referred to above [e.g. [20,21].

The selection of indicators also reflects the availability of reliable and established data sets of alcoholrelated harm indicators in the NT prior to, and following the implementation of LWA.

\section{Prevalence of hazardous and harmful alcohol consumption}

The Territory Health Services conducted or commissioned household surveys on alcohol consumption in
1992,1993 [22] and 1997 [23] with a smaller survey conducted in 1994 [24]. The sample size and geographic coverage of these surveys varied between these periods. Fortunately, the 1992 survey was completed just before the introduction of the LWA levy.

At the outset of LWA it was predicted by some that the additional levy on alcohol would lead to an escalation in both home brewing and inter-state mail order purchases of alcohol. Each of the above surveys inquired about whether respondents acquired alcohol by these means in order to examine the validity of this prediction.

\section{Per capita consumption of alcohol}

Per capita consumption of alcohol has been shown to reflect changes in patterns of harm (e.g. $[1,2,5])$. The actual per capita annual alcohol consumption in the NT was estimated using NT Liquor Commission data on litres of different beverages purchased by liquor licensees. To convert these data into estimates of litres of absolute alcohol the following conversions were used: wine, 11.9\%; high-strength beer (above 3\%) 4.8\%; low-strength beer (below 3.1\%) 2.5\%; unmixed spirits, $38.5 \%$; and mixed spirits, $5 \%$.

Since the definitions of what constituted low and high strength beer varied during the study period, it was necessary to combine all high and low beer purchases. Key informants from the NT Liquor Commission also identified that, prior to 1992 , aggregates based on high and low beer were unreliable thus requiring all beer to be combined. The percentage alcohol estimate employed for all beer was $4.24 \%$ determined from a weighted average of the top 18 (14 $>3 \% ; 4<3 \%$ ) selling NT beers identified by the NT Government Sessional Committee [7].

To allow for population changes, estimates of licensee purchases of pure alcohol were divided by Australian Bureau of Statistics estimates of NT residential population aged $15+$ years for each financial year, producing estimates of adult per capita consumption of pure alcohol.

\section{Road crash injuries}

The NT Department of Transport and Works provided data on the number of injuries and fatalities resulting from road crashes collected by NT Police between 1984 and 1997. In the NT only $45 \%$ of all drivers involved in road crashes were tested for their 
BAC during the study period. As a consequence, a surrogate measure of alcohol-related crashes was developed.

As many as $80 \%$ of single vehicle night-time fatal and non-fatal crashes involve prior consumption of alcohol by the driver [25]. In the NT during the period examined, Thursdays were social security pay days and the LWA programme staff advised these are traditionally associated with heavy drinking. Tests were conducted on the timing of the 18024 crashes to have occurred between 1984 and 1997 to examine whether crashes on Thursdays, Fridays and Saturdays would be more likely to occur at night-time than other days of the week. A test of two independent proportions showed that the percentage of road injuries occurring at night-time was significantly higher on Thursdays, Fridays and Saturdays (45\%) than on other days of the week (37\%) $(Z=10.7, p<0.001)$. To maximize the contrast, a control non-alcohol-related crash indicator of day-time crashes on Sundays to Wednesdays was selected.

This surrogate method was applied for fatal crash injuries and crashes resulting in injuries requiring hospital treatment as recorded by police. Data on rates of crashes occurring between 6.01 a.m. and 5.59 p.m. on Mondays, Tuesdays and Wednesdays were used as a control series.

\section{Alcohol-related mortality}

Epidemiological evidence shows that hazardous and harmful alcohol use contributes substantially to death, injury and illnesses [26]. Some conditions are related explicitly to alcohol use, in other cases alcohol is known to be a contributing cause. The incidence of all these alcohol-related causes of death was used to create composite measures of the extent of alcohol-related harm over the study period. Furthermore, these alcohol-related causes were separated into chronic and acute conditions. Acute health problems are those related to episodes of intoxication, where as overall levels of consumption are associated with chronic harms. Included in acute conditions were all intentional and unintentional injuries and poisonings. Cancers, strokes, liver disease and other conditions caused by long-term heavy drinking were classified as chronic conditions.

Morbidity and mortality data were obtained from the Territory Health Services. Mortality data included over 8800 deaths occurring between mid-1985 and mid-1996. Approximately $28 \%$ of these deaths were from causes shown by English et al. [24] to be at least partly caused by hazardous or harmful consumption of alcohol. Unfortunately, hospital morbidity for the years 1988/89 to 1991/92 were missing. Results for these data were reported by Chikritzhs et al. [5] and will not be discussed further here.

Aetiological fractions were calculated specifically for the NT for each year of the study. An alcohol aetiological fraction is the proportion of cases considered to be caused by alcohol and is estimated by knowing (i) the increased risk of an illness occurring for high-risk drinkers and (ii) the prevalence of highrisk drinking in the community being studied. Local data on high-risk drinking were taken from the 1992 NT Household Survey [22] for different age and sex groups. Alcohol sales data from the NT Liquor Licensing Commission were then used to adjust these estimated prevalences of high-risk drinking for each year of the study using a formula described by Chikritzhs et al. [2]. Relative risks (which should be reasonably generalizable across Australian communities) were drawn from published meta-analyses provided by English et al. [24] for the various chronic alcohol-caused conditions indicators. These were then combined with the estimates of the prevalence of hazardous and harmful drinking for the NT to recalculate aetiological fractions for the NT. The aetiological fractions calculated by English et al. [24] for acute conditions were also adjusted by annual estimates of per capita alcohol consumption in the NT (see [2]).

\section{Statistical analysis of trends in harm indicator data}

The main analytical strategy was to compare trends in the alcohol-related harm indicators with the control data on non-alcohol-related harms. Where appropriate time-series ARIMA analysis was employed, otherwise multiple linear regression analysis was applied. Time-series ARIMA analysis measures and controls for the degree of correlation in a temporal series of data between measures in time. This is known as serial autocorrelation and may be positive or negative. If there is no significant serial autocorrelation it is generally appropriate to use multiple linear regression. These statistical techniques were used to test the hypothesis that the beginning of LWA was associated with a greater reduction in alcohol-related harm than in nonalcohol-related control data. 
Table 1. Drinking risk levels for males and females in the Northern Territory determined from annual urban surveys

\begin{tabular}{lrr} 
Level of consumption & Males & Females \\
\hline $1992(n=1090)$ & & \\
$\quad$ Did not drink in past week & $22 \%$ & $42 \%$ \\
$\quad$ Responsible & $48 \%$ & $46 \%$ \\
Hazardous & $16 \%$ & $8 \%$ \\
Harmful & $14 \%$ & $4 \%$ \\
1993 $n=1296)$ & & \\
Did not drink in past week & $24 \%$ & $45 \%$ \\
Responsible & $52 \%$ & $46 \%$ \\
Hazardous & $11 \%$ & $8 \%$ \\
Harmful & $13 \%$ & $2 \%$ \\
1997 ( $n=1582)$ & & \\
Did not drink in past week & $31 \%$ & $48 \%$ \\
Responsible & $47 \%$ & $42 \%$ \\
Hazardous & $10 \%$ & $8 \%$ \\
Harmful & $12 \%$ & $2 \%$ \\
\end{tabular}

\section{Results}

\section{Hazardous and harmful alcohol consumption}

The surveys of alcohol consumption in the NT between 1992 and 1997 [22] suggested reductions in high risk consumption following LWA, particularly for men. Table 1 shows a sustained increase in the number of male drinkers reporting drinking at responsible levels and decreases particularly in drinking at hazardous or harmful levels $(30-22 \%$, or $-26.7 \%)$. Women showed similar though smaller changes $(12-10 \%$, or $-16.7 \%)$. These data suggest an immediate benefit which was then sustained.

\section{Per capita consumption}

Prior to mid-1990 there were no wholesale purchase data available for the NT. Between 1980/81 and 1989/90 NT per capita consumption was modelled from national levels obtained from World Drink Trends [27] (Fig. 1). It was assumed in doing this that per capita consumption in the NT maintained the same ratio to national levels as in 1990/1991. The above estimates of per capita consumption are based on liquor licensing returns from retailers and wholesalers. They take no account of either home-made drinks or interstate purchases made by individuals. Table 2 summarizes the responses from drinkers to the three larger surveys mentioned above regarding their use of these in the 3 months prior to each survey. If anything these responses suggest a slight reduction in consumption of home-brewed beer and an increase in interstate purchases. However, the latter are still at a low level and the amounts reported to have been consumed were quite small [22]. These data suggest that the reductions in recorded per capita consumption reported here are not an artefact

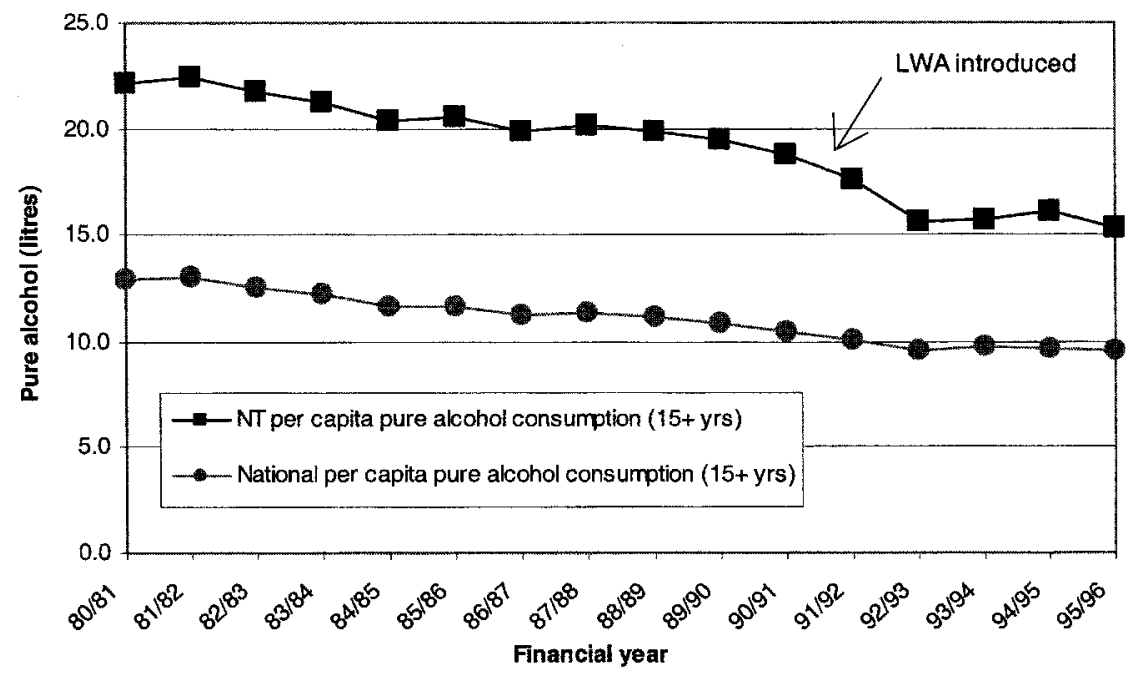

Figure 1. Annual per capita consumption of pure alcohol in the NT for people aged $15+$ years between 1980/81 and $1995 / 96$. 
Table 2. Percentage of drinkers consuming home-brewed beer or mail-order alcohol in past 3 months (weighted data)

$$
\begin{aligned}
& \text { Type of alcohol } 1992 \quad 1993 \quad 1997 \\
& (n=1088)(n=1293) \quad(n=1582)
\end{aligned}
$$

\begin{tabular}{llll}
\hline Home-brew & $7 \%$ & $8 \%$ & $6 \%$ \\
Mail-order & $3 \%$ & $3 \%$ & $6 \%$ \\
\hline
\end{tabular}

of a compensatory increase in alcohol consumption from other sources.

\section{Road injury data}

Alcohol-related non-fatal road crash injuries requiring hospitalization

For this analysis the basic unit under examination was the rate of non-fatal road injuries requiring hospitalization and occurring at quarterly intervals over the study period. Since road injury rates were calculating per 10000 NT licensed drivers, injuries were drawn from all cases except where the injured party was a pedestrian or a bicycle rider (approximately 13.2\%).

As shown in Fig. 2, while night-time injuries requiring hospitalization appeared to decline markedly about the time of LWA implementation, rates for the control day-time injuries remained relatively stable throughout the study period.
The impact of LWA on road injuries requiring hospital treatment that occurred on Thursday, Friday and Saturday nights was examined using multiple linear regression. Other independent variables included; the control series-day-time minor crash injury rates, as well as the introduction of 0.05 BAC legislation and the cask wine levy. This test was appropriate as the Durban-Watson test found no significant serial autocorrelation. Before the introduction of LWA, the mean seasonally adjusted quarterly rate of non-fatal night-time road injuries requiring hospitalization was approximately 2.94 per 10000 licensed drivers. Subsequent to the introduction of LWA the mean night-time road injury rate declined by $26.2 \%$ to 2.17 injuries per quarter per 10000 licensed drivers. For day-time minor road injuries the mean rate of injury prior to LWA was 6.01 per quarter increasing slightly $(6 \%)$ to 6.37 injuries per quarter per 10000 drivers in the after period.

As shown in Table 3, the association between LWA and night-time crash injury rates was negative and highly significant $(t=-3.3(49), p<0.005)$. Importantly, however, when adjusted for concurrent changes in day-time crash injury rates (by inclusion as an independent regressor in the analysis) this effect declined only slightly and remained significant $(t=$ -3.2(48), $p<0.005$ ). Additionally, after adjustment for the implementation of $0.05 \mathrm{BAC}$ legislation/cask wine levy, the association between LWA and night-

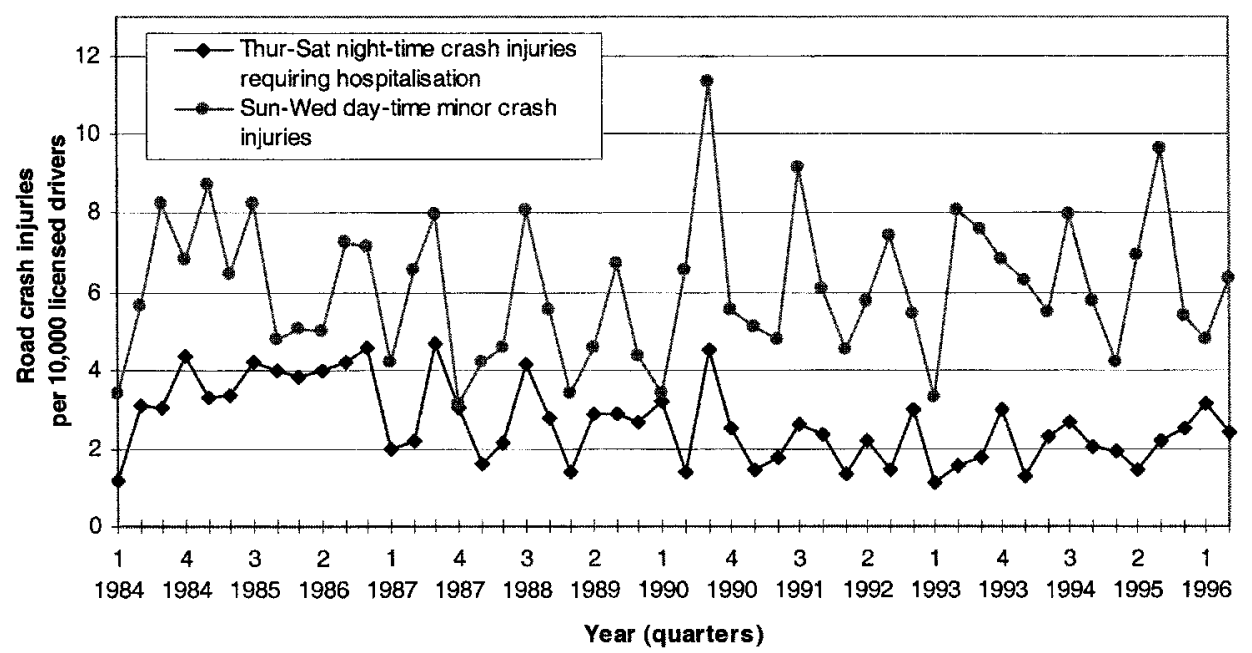

Figure 2. Trends in quarterly road crash injury rates requiring hospitalization occurring Thursday-Saturday night-time (alcoholrelated) and crash injury rates for minor injuries occurring Sunday-Wednesday day-time (non-alcohol-related). 
Table 3. Association between LWA and night-time Thursday-Saturday crash injury rates, including adjustment for day-time SundayWednesday crash injury rates and the introduction of 0.05 BAL legislation/cask wine levy

$95 \%$ confidence interval for B

\begin{tabular}{|c|c|c|c|c|c|c|c|}
\hline Variable(s) entered & $\begin{array}{c}\text { Adjusted } R^{2} \\
\text { for model }\end{array}$ & $\begin{array}{l}\text { Stnd. B } \\
\text { coef. }\end{array}$ & $\begin{array}{c}\text { B } \\
\text { Estimate }\end{array}$ & Lower & Upper & $t$ & Sig. \\
\hline LWA only & $13.3 \%$ & -0.388 & -0.765 & -1.292 & -0.237 & -3.311 & 0.002 \\
\hline $\begin{array}{l}\text { LWA adjusted for } \\
\text { day-time minor } \\
\text { road injuries }\end{array}$ & $17.7 \%$ & -0.420 & -0.828 & -1.346 & -0.309 & -3.211 & 0.002 \\
\hline $\begin{array}{l}\text { LWA adjusted for } \\
0.05 \text { campaign/cask } \\
\text { wine levy only }\end{array}$ & $13.9 \%$ & -0.480 & -0.946 & -1.559 & -0.332 & -3.102 & 0.003 \\
\hline $\begin{array}{l}\text { LWA adjusted for } \\
\text { day-time minor } \\
\text { road injuries and } \\
0.05 \text { legislation/ } \\
\text { cask wine levy }\end{array}$ & $18.1 \%$ & -0.506 & -0.999 & -1.600 & -0.397 & -3.344 & 0.002 \\
\hline
\end{tabular}

time injury rates remained significant at the 0.01 level $(t=-3.1(48), p<0.005)$.

It was estimated that LWA reduced the rate of alcohol-related road crash injuries by between 1.2 and 5.4 injuries per 10000 licensed drivers per year. Over the 4 years following the introduction of LWA, it was estimated from the above model median number of injuries saved was 125 (95 CI: 46-203). Overall, the median proportion of hospitalised road injuries saved was $28 \%$.

\section{Fatal road crash injuries}

As a consequence of relatively low volumes of fatal crashes and that $71 \%$ of those tested had BACs in excess of 0.05 [4] total driver fatalities were used as an additional alcohol harm indicator. Minor day-time crash injuries occurring between Sundays and Wednesdays were used as controls. Minor crashes were selected from two types of road injury recorded on the NT traffic database-those which did not require any hospital treatment, and those which only required emergency room treatment but which did not require admission to hospital.

The Durban-Watson test found no significant serial autocorrelation in the quarterly rates of fatal crashes between 1984 and 1996 and hence multiple regression analysis was employed to examine the impact of LWA. As indicated in Fig. 3, prior to the introduction of LWA the mean quarterly crash fatality rate was 1.48 deaths. Subsequent to LWA introduction the mean quarterly rate was reduced by $34 \%$ to approximately 0.98 deaths. For minor control injuries the rate prior to LWA was 6.01 injuries per quarter, which increased slightly by $6 \%$ to 6.37 injuries per quarter.

As shown in Table 4, the association between LWA and crash fatality rates was negative and highly significant at the 0.05 level $(t=-3.2(49), p<$ $0.005)$. Adjustment for concurrent trend in day-time minor injuries and the implementation of the 0.05 campaign and cask wine levy did not affect the significance of the relationship between LWA and fatality rates $(t=-3.3(48), p<0.005)$.

With $95 \%$ confidence, the effect of LWA on the rate of fatal crash injuries was to decrease fatality rates significantly from between approximately two to eight deaths per 10000 licensed drivers per year. Over the 4 years subsequent to the introduction of LWA, the estimated median number of lives saved was approximately 77, within an upper $95 \%$ confidence limit of 125 and a lower limit of 29 lives. An average of 35\% of expected road fatalities were saved over the 4-year period of the LWA programme. 


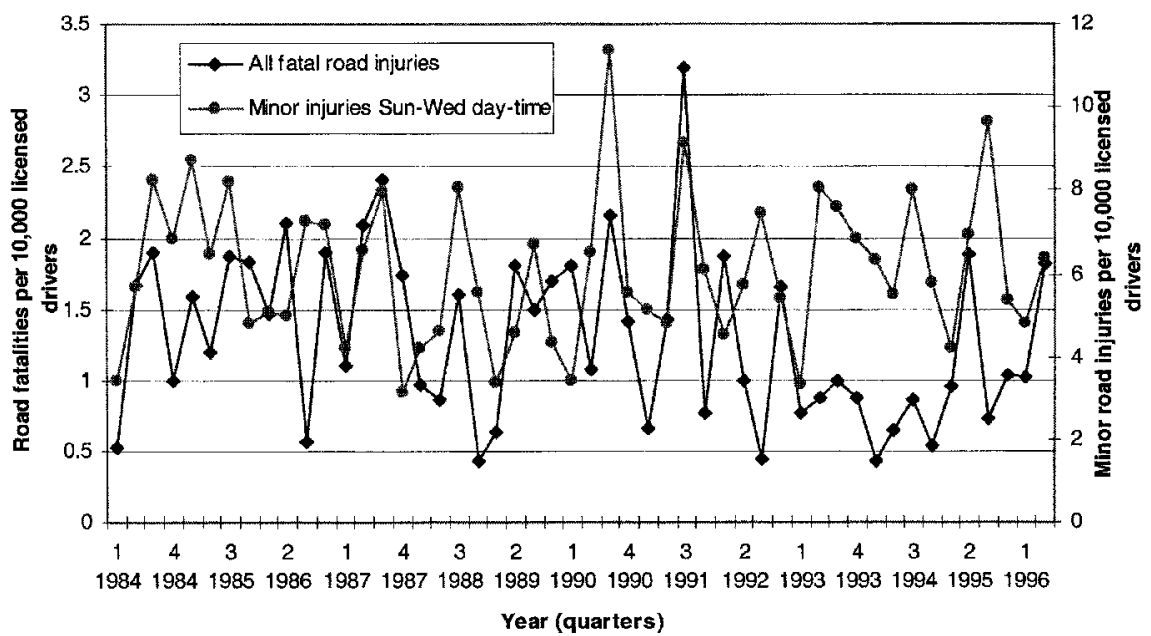

Figure 3. Trends in quarterly fatal road crash injury rates (alcohol-related) and rates of minor injuries occurring during day-time hours between Sunday and Wednesday (non-alcohol-related).

\section{Alcohol-related mortality}

Alcohol-related mortality excluding fatal road injuries

Prior to the introduction of LWA the mean death rate for all alcohol-related conditions (adjusted by aetiological fraction) was 1.21 deaths per quarter per 10000 people over the age of 15 years (deseasonalized). Subsequent to LWA the mean quarterly death rate of all alcohol-related conditions was reduced by $10.7 \%$ to 1.08 . For deaths from

Table 4. Association between LWA and all fatal road crash injury rates, including adjustment for day-time minor road crash injury rates occurring Sunday-Wednesday and the introduction of 0.05 BAL legislation/cask wine levy

$95 \%$ confidence interval for B

\begin{tabular}{|c|c|c|c|c|c|c|c|}
\hline Variable(s) entered & $\begin{array}{c}\text { Adjusted } R^{2} \\
\text { for model }\end{array}$ & $\begin{array}{l}\text { Stnd. B } \\
\text { coef. }\end{array}$ & $\begin{array}{c}\text { B } \\
\text { Estimate }\end{array}$ & Lower & Upper & $t$ & Sig. \\
\hline LWA only & $15.7 \%$ & -0.418 & -0.497 & -0.811 & -0.183 & -3.184 & 0.003 \\
\hline $\begin{array}{l}\text { LWA adjusted for } \\
\text { minor crash } \\
\text { injuries occurring } \\
\text { during day-time }\end{array}$ & & & & & & & \\
\hline Sun to Wed only & $15.4 \%$ & -0.433 & -0.515 & -0.833 & -0.194 & -3.268 & 0.002 \\
\hline $\begin{array}{l}\text { LWA adjusted for } \\
0.05 \text { campaign/cask } \\
\text { wine levy only }\end{array}$ & $19.0 \%$ & -0.550 & -0.655 & -1.014 & -0.296 & -3.670 & 0.001 \\
\hline $\begin{array}{l}\text { LWA adjusted for } \\
\text { minor day-time } \\
\text { injuries and } 0.05 \\
\text { legislation/cask } \\
\text { wine levy }\end{array}$ & $18.6 \%$ & -0.563 & -0.670 & -1.013 & -0.308 & -3.726 & 0.001 \\
\hline
\end{tabular}


Table 5. Association between LWA and adjusted quarterly alcohol-related mortality rates (not including road fatalities), including adjustment for non-alcohol related mortality rates and the introduction of 0.05 BAL legislation/cask wine levy

$95 \%$ confidence interval for B

\begin{tabular}{|c|c|c|c|c|c|c|c|}
\hline Variable(s) entered & $\begin{array}{l}\text { Adjusted } R^{2} \\
\text { for model }\end{array}$ & $\begin{array}{l}\text { Stnd. B } \\
\text { coef. }\end{array}$ & $\begin{array}{c}\text { B } \\
\text { Estimate }\end{array}$ & Lower & Upper & $t$ & Sig. \\
\hline LWA only & $3 \%$ & -0.232 & -0.130 & -0.299 & 0.040 & -1.545 & 0.130 \\
\hline $\begin{array}{l}\text { LWA adjusted for } \\
\text { trend in death rate } \\
\text { among all other } \\
\text { conditions only }\end{array}$ & $22.4 \%$ & -0.454 & -0.254 & -0.423 & -0.085 & -3.035 & 0.004 \\
\hline $\begin{array}{l}\text { LWA adjusted for } \\
0.05 \text { campaign/cask } \\
\text { wine levy only }\end{array}$ & $12.1 \%$ & -0.422 & -0.236 & -0.423 & -0.049 & -2.553 & 0.015 \\
\hline $\begin{array}{l}\text { LWA adjusted for all } \\
\text { above }\end{array}$ & $25.4 \%$ & -0.553 & -0.310 & -0.489 & -0.130 & -3.484 & 0.001 \\
\hline
\end{tabular}

all other conditions the mean quarterly mortality rate was 12.5 prior to April 1992 and 11.3 following the introduction of the project, a reduction of $9.6 \%$.

Quarterly rates of all combined alcohol-related deaths, adjusted by aetiological fraction and expressed as a rate per $10000 \mathrm{NT}$ resident people over the age of 15 years comprised the dependent variable in multiple linear regression analysis. The implementation of LWA was examined as an independent variable while controlling for the corresponding trend in quarterly death rates from all other conditions as well as the implementation of the 0.05 campaign/cask wine levy. Residuals were examined for significant serial auto-correlation with no evidence of negative or positive correlation apparent.

As shown in Table 5, the association between LWA and alcohol-related mortality rate without further adjustment for trend in non-alcohol related conditions was not significant. However, as indicated in Fig. 4, shortly after LWA was introduced, quarterly alcoholrelated death rates declined while by comparison, nonalcohol-related controls remained relatively stable. Thus, when adjusted for concurrent trends in overall non-alcohol-related quarterly death rates, the strength of the association between LWA and the decline in alcohol-related deaths was increased, producing a significant result $(t=-3.03(42), p=<0.005)$. As apparent from Fig. 4, at about the time of the introduction of 0.05 legislation and the cask wine levy, over 2.5 years after the introduction of LWA, alcoholrelated mortality rates began to rise. Subsequently, adjustment for the 0.05 legislation/cask wine period only also had the effect of increasing the strength of the association between LWA and the decline in quarterly alcohol-related death rates $(t=-2.55(42)$, $p<0.05$ ).

Thus, with $95 \%$ confidence, it can be concluded that the effect of LWA on mortality was to significantly decrease the rate of alcohol-related deaths from between approximately 0.3 and 1.7 deaths per year per 10000 people over the age of 15 years. Over the 4 years subsequent to the introduction of LWA, the estimated median number of lives saved was $52(95 \%$ CI: 17-86).

Tables 6 and 7 presents the results of separate multiple linear regression tests of the association between LWA and quarterly mortality rated due to chronic and acute alcohol-related conditions while adjusted for concurrent changes in quarterly death rate from non-alcohol-related conditions. As can be seen below, there was only a significant impact of LWA demonstrated for acute mortality.

The relationship between mortality rate from chronic alcohol-related conditions and LWA failed to reach significance at the 0.05 level $(t=-1.63(45)$, ns). However, the association between LWA and death rate from acute alcohol-related conditions was found to 


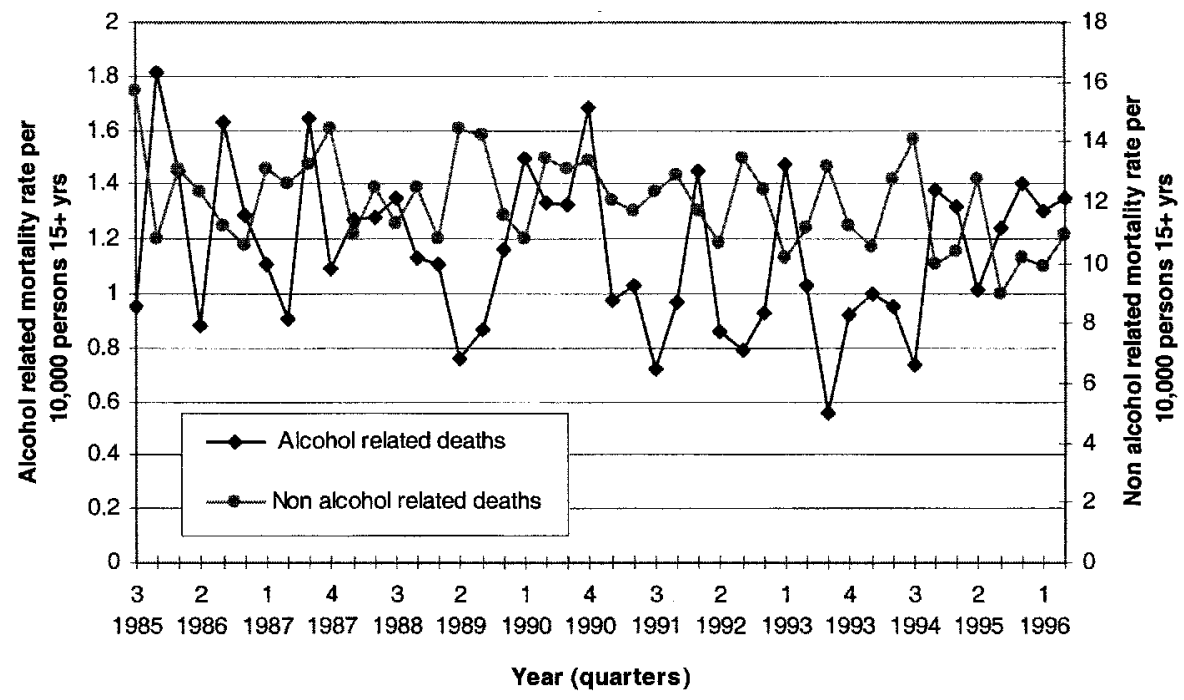

Figure 4. Trends in quarterly mortality rates for all combined alcohol-related deaths (not including road fatalities) and non-alcoholrelated deaths.

be significant at the 0.01 level $(t=-2.76(42), p<$ $0.01)$.

\section{Summary and conclusions}

When taking the above points into account, it is apparent from the various datasets considered that the occurrence of a substantial reduction in alcohol-related harm in the NT following the introduction of the Living With Alcohol programme. The controlled analyses of trends resulted in estimated effect sizes of between $19 \%$ for alcohol-related deaths other than from road crashes and $34.5 \%$ for road deaths. These large and highly significant changes are consistent with the observed reductions in per capita alcohol con- sumption over the period of $22 \%$ and substantial reductions in self-reported consumption in survey data following introduction of LWA. The drop in the percentage of males drinking at hazardous or harmful levels between 1992 and 1997 was 27\% (or a drop from $30 \%$ to $22 \%$ of all males).

Reductions in acute alcohol-related harm are more likely to be observed in the short term and it may take many years for long-term benefits for conditions such as liver cirrhosis to be observed. However, there are well documented instances in which chronic harms have responded promptly to reductions in per capita consumption (see [9]). It is reported elsewhere that LWA was also associated with substantial declines in rates of chronic alcohol-related morbidity, although

Table 6. Association between LWA and seasonally adjusted quarterly mortality rates due to chronic and acute conditions (not including road fatalities) adjusted for concurrent trends in mortality rate for non-alcohol-related conditions

$95 \%$ confidence interval for B

\begin{tabular}{|c|c|c|c|c|c|c|c|}
\hline Variable(s) entered & $\begin{array}{c}\text { Adjusted } R^{2} \\
\text { for model }\end{array}$ & $\begin{array}{c}\text { Stnd. B } \\
\text { coef. }\end{array}$ & $\begin{array}{c}\text { B } \\
\text { Estimate }\end{array}$ & Lower & Upper & $t$ & Sig. \\
\hline Chronic & $14.8 \%$ & -0.255 & -0.101 & -0.227 & 0.024 & -1.629 & 0.111 \\
\hline Acute & $12.1 \%$ & -0.439 & -0.147 & -0.255 & -0.039 & -2.759 & 0.009 \\
\hline
\end{tabular}


Table 7. Summary of effect sizes of LWA on alcohol-related harm indicators determined by multivariate analysis

\section{Harm indicator}

$\mathrm{N}$ cases

(by aetiological fractions if used)
Statistically derived estimates of $\%$ change against control variables
Mortality

Road deaths only

Other deaths

Acute

Chronic

Total other deaths

Road injuries given hospital care

Alcohol consumption

$\%$ males drinking hazardously

Per capita alcohol consumption
84.4 during LWA

108.5 during LWA

108.8 during LWA

217.3 during LWA

18024

(1984-97)

Survey sample $=2670$

Complete wholesale sales data
$-34.5 \%, p<0.005$

(95\% CI: $12.8-39.1$ )

$-23.4 \%, p<0.01$

(95\% CI: $7.5-34.6$ )

ns

$-18.9 \%, p<0.05$

(95\% CI: $7.2-34.6$ )

$-28.3 \%, p<0.005$

(95\% CI: $12.8-39.1$ ) several years of data were missing and the results are difficult to interpret.

There was no evidence of an increasing trend in benefits since the initiation of the programme. The pattern of improvement seems to reflect a strong and immediate benefit flowing directly from the imposition of the alcohol levy at the very beginning of the programme. There are a priori reasons for supposing that the dampening effect of the alcohol levy on alcohol consumption would begin to decline over time as a function of increasing incomes and cross-border purchase patterns. The extent of this, however, is hard to determine. The fact that there was evidence of some benefits being sustained throughout the study period is at least consistent with there having been direct benefits from the programmes implemented by LWA.

In relation to the separate effects of the introduction of the 0.05 legal BAC limit and the cask wine levy, there was limited opportunity in the time series of data available to test for specific effects from these. Longerterm studies are required to examine the impact of these potentially important initiatives. A separate study [28] has found that sales of cask wine dropped by about one-third following the introduction of the cask wine levy in the NT in 1995.

Another explanation for the substantial changes in alcohol-related harm observed could be connected with changes in overall economic activity. The early 1990s was a time of recession in Australia. Published indicators of economic activity in Australian states showed a pattern of declining activity with a trough in 1992 and an upsurge in 1993 and 1994 [29]. This matches fairly well the patterns observed in the NT in this study for road crashes. The controlled design of the present study, however, means that differences were demonstrated between alcohol-related and non-alcohol-related harm indicators, i.e. if the recession had an impact it did so differentially on alcohol-related events - a plausible explanation given that previous studies have found that high-risk alcohol consumption is especially reduced during a recession [30].

A further factor independent of the LWA programme or the levy was the fact that in the early 1990s the major brewers introduced a range of new low-alcohol beers which were marketed aggressively. This marketing would have had an impact in the NT and may well have complemented the LWA initiatives (e.g. [31]). In summary, there is evidence of substantial health benefits associated with the period following the introduction of LWA which were especially evident in relation to acute morbidity and mortality. Both road safety and health data independently substantiate this conclusion. The extent to which these benefits can be entirely attributed to the LWA levy, the programmes funded by 
LWA, or other initiatives or changes in economic activity is unclear.

\section{Acknowledgements}

This research was funded by the NT Government's Living With Alcohol programme and the National Drug Strategy. Many people have assisted with our work and we apologize if not all are mentioned by name. In particular we would like to thank Don Sheen of Vehicle and Accident Management Services at the Northern Territory Department of Transport and Works; Karen Dempsey, Michael Pearse and all staff, at the Epidemiology branch of Territory Health Services; Chris Hoffman and Chris Shaw of the Northern Territory Liquor Licensing Commission; Ian Hambour of the Motor Vehicle Registry Department of Transport and Works; Dr Peter d'Abbs of Menzies School of Health Research as well as Ian Crundall and the Research and Evaluation section of the Northern Territory Living With Alcohol programme. We also gratefully acknowledge the assistance of Susan Wilson for formatting the final version of this paper.

\section{References}

[1] Chikritzhs T, Stockwell TR, Heale P, Dietze P, Webb M. Trends in alcohol-related road injury in Australia, 1990-1997. National Alcohol Indicators Project, bulletin no. 2. Perth, WA: National Drug Research Institute, Curtin University of Technology, 2000.

[2] Chikritzhs T, Jonas H, Heale P, Stockwell T, Dietze P, Hanlin K, Webb M. National Alcohol Indicators Project, technical report no. 1: Alcohol-caused deaths and hospitalisations in Australia, 1990-1997. Perth, WA: National Drug Research Institute, Curtin University of Technology, 2000.

[3] World Health Organization. Global status report on alcohol. Geneva: Substance Abuse Department, World Health Organization, 2000.

[4] World Health Organization. International guide for monitoring alcohol consumption and harm. Geneva: Mental Health and Substance Abuse Department, WHO, 2001.

[5] Chikritzhs T, Jonas H, Heale P, Dietze P, Hanlin K, Stockwell T. Alcohol-caused deaths and hospitalisations in Australia. National Alcohol Indicators Project, bulletin no. 1. Perth, WA: National Drug Research Institute, Curtin University of Technology, 1999.

[6] Chikritzhs T, Stockwell T, Heale P, Dietze P, Webb M. National Alcohol Indicators Project, technical report no. 2: Trends in alcohol-related road injury, 1990-1997. Perth, WA: National Drug Research Institute, Curtin University of Technology, 2000.

[7] Legislative Assembly of the Northern Territory. Measures for reducing alcohol use and abuse in the Northern Territory: Interim report of the sessional Committee on Use and Abuse of Alcohol by the Community. Darwin: Northern Territory Government, 1991.

[8] Crundall I. The Northern Territory Living With Alcohol program: progress to July 1993. Darwin, NT: Department of Health and Community Services, 1994.

[9] Edwards G, Anderson P, Babor TF, et al. Alcohol policy and the public good. Cambridge, UK: Cambridge University Press, 1994.

[10] Österberg E. Effects of price and taxation. In: Heather N, Peters T, Stockwell T, eds. International handbook on alcohol problems and dependence. UK: John Wiley and Sons, 2001:685-98.

[11] Stockwell T, Masters L, Philips M, et al. Consumption of different alcoholic beverages as predictors of local rates of night-time assault and acute alcohol-related morbidity. Aust NZ J Public Health 1998;22 : 237-42.

[12] Holder HD, Blose JO. The reduction of health care costs associated with alcoholism treatment: a fourteen year longitudinal study. Ann Rev Addit Res Treat 1994;3:367-80.

[13] Stewart L, Casswell S. Media advocacy for alcohol policy support: results from the New Zealand community action project. Health Promotion International, 1993;8:167-75.

[14] Homel R. Policing and punishing the drinking driver: study of general and specific deterrents. New York: Springer-Verlag, 1988.

[15] Rydon P, Stockwell T. Local regulation and enforcement strategies for licensed premises. In: Plant $\mathrm{M}$, Single E, Stockwell T, eds. Alcohol: minimizing the harm-what works? New York: Free Association Books, 1997.

[16] Chikritzhs T, Stockwell T, Masters L. Evaluation of the public health and safety impact of extended trading permits for Perth hotels. Technical report. Perth, WA: National Centre for Research into the Prevention of Drug Abuse, Division of Health Sciences, Curtin University of Technology, 1997.

[17] d'Abbs P, Forner J, Thomsen P. Darwin nightclubs: a review of trading hours and related issues. Darwin, Australia: Menzies School of Public Health, 1994.

[18] Gray D, Saggers S, Atkinson D, Sputore B, Bourbon D. Beating the grog: an evaluation of the Tennant Creek Liquor Licensing Restrictions. Aust NZ J Public Health 2000;24:39-44.

[19] National Expert Advisory Committee on Alcohol. Alcohol Action Plan. Canberra: Commonwealth Department of Health and Aged Care, 2000. 
[20] Jonas H, Dietze P, Rumbold G, Hanlin K, Cvetkovski S, Laslett A. Associations between alcohol-related hospital admissions and alcohol consumption in Victoria, Australia: influence of sociodemographic factors. Aust J Public Health, 1999;23:272-9.

[21] Stevenson RJ, Lind B, Weatherburn D. The relationship between alcohol sales and assault in New South Wales, Australia. Addiction 1999;94:397-410.

[22] D'Abbs P. Alcohol Consumption in the Northern Territory, 1992-1993: an analysis of trends revealed by two surveys. Darwin, NT: Menzies School of Public Health, 1993.

[23] Bertram S, Crundall I. Summary of household survey of alcohol consumption and related attitudes February-March 1997. Darwin, NT: Living With Alcohol Program, 1997.

[24] Crundall I. 1994 household survey of alcohol consumption in the Northern Territory. Darwin, NT: Living With Alcohol Program, 1997.

[25] Zador PL, Lund AK, Fields M, Weinberg K. Fatal crash involvement and laws against alcohol-impaired driving. Washington, DC: Insurance Institute for Highway Safety, 1988.
[26] English DR, Holman CDJ, Milne E, et al. The quantification of drug caused morbidity and mortality in Australia 1995. Canberra: Department of Human Services and Health, 1995.

[27] World Drink Trends. International beverage alcohol consumption and production trends. Henley-onThames: NTC Publications, 1998.

[28] Gray D, Chikritzhs T, Stockwell TR. The Northern Territory's cask wine levy: health and taxation policy implications. Aust NZ J Public Health 1999;23: 651-653.

[29] Boehm EA. New economic indicators and business cycle chronologies for the Australian states. Institute of Applied Economic and Social Research, working paper series 2/96. Victoria: University of Melbourne, 1996.

[30] Kendell R, de Roumanie M, Ritson EB. Effects of economic changes on Scottish drinking habits 1978-82. Br J Addict 1983;78:365-80.

[31] Gruenewald P, Stockwell T, Beel A, Dyskin E. Beverage sales and drinking and driving: the role of on-premise drinking places. J Stud Alcohol 1999; $60: 47-53$. 